\title{
Binding Sites of $\gamma$-Secretase Inhibitors in Rodent Brain: Distribution, Postnatal Development, and Effect of Deafferentation
}

\author{
Xiao-Xin Yan, ${ }^{1}$ Tong Li, ${ }^{2}$ Cynthia M. Rominger, ${ }^{1}$ Shimoga R. Prakash, ${ }^{1}$ Philip C. Wong, ${ }^{2}$ Richard E. Olson, ${ }^{1}$ \\ Robert Zaczek, ${ }^{1}$ and Yu-Wen $\mathrm{Li}^{1}$ \\ ${ }^{1}$ Bristol-Myers Squibb Company, Pharmaceutical Research Institute, Neuroscience Drug Discovery, Wallingford, Connecticut 06492, and ${ }^{2}$ Department of \\ Pathology and Neuroscience, Johns Hopkins University School of Medicine, Baltimore, Maryland 21205
}

\begin{abstract}
$\gamma$-Secretase is a multimeric complex consisted of presenilins (PSs) and three other proteins. PSs appear to be key contributors for the enzymatic center, the potential target of a number of recently developed $\gamma$-secretase inhibitors. Using radiolabeled and unlabeled inhibitors as ligands, this study was aimed to determine the in situ distribution of $\gamma$-secretase in the brain. Characterization using PS- 1 knock-out mouse embryos revealed 50 and $80 \%$ reductions of $\gamma$-secretase inhibitor binding density in the heterozygous (PS-1 ${ }^{+/-}$) and homozygous (PS-1 ${ }^{-l-}$ ) embryos, respectively, relative to the wild type $\left(\mathrm{PS}-1^{+/+}\right)$. The pharmacological profile from competition binding assays suggests that the ligands may target at the $\mathrm{N}$ - and C-terminal fragments of PS essential for $\gamma$-secretase activity. In the adult rat brain, the binding sites existed mostly in the forebrain, the cerebellum, and discrete brainstem areas and were particularly abundant in areas rich in neuronal terminals, e.g., olfactory glomeruli, CA3- hilus area, cerebellar molecular layer, and pars reticulata of the substantia nigra. In the developing rat brain, diffuse and elevated expression of binding sites occurred at the early postnatal stage relative to the adult. The possible association of binding sites with neuronal terminals in the adult brain was further investigated after olfactory deafferentation. A significant decrease with subsequent recovery of binding sites was noted in the olfactory glomeruli after chemical damage of the olfactory epithelium. The findings in this study support a physiological role of PS or $\gamma$-secretase complex in neuronal and synaptic development and plasticity.
\end{abstract}

Key words: presenilins; $\gamma$-secretase inhibitor; $\beta$-amyloid precursor protein; Alzheimer; neurogenesis; neuroplasticity; autoradiography

\section{Introduction}

Currently, the most compelling hypothesis on the etiology of Alzheimer's disease (AD) centers on the overproduction of $\beta$-amyloid peptide $(\mathrm{A} \beta)$ generated through sequential cleavages of the amyloid precursor protein (APP) by two proteases, $\beta$ - and $\gamma$-secretases (for review, see Verbeek et al., 1997; Selkoe, 2001). An aspartyl protease, termed $\beta$-site APP-cleaving enzyme, was identified as a $\beta$-secretase (Vassar et al., 1999; Yan et al., 1999). $\gamma$-Secretase is now considered a multimeric complex consisting of presenilins (PS-1 and PS-2), Aph-1, Pen-2, and nicastrin (De Strooper, 2003, Kimberly et al., 2003; Li et al., 2003). Although all these components are essential for the formation of a functional complex, PSs seem to be the key contributors for the active site of the enzyme. Thus, $\gamma$-secretase activity is abolished after knockout of PS genes (De Strooper et al., 1998; Herreman et al., 2000; Kimberly et al., 2003) or mutations of its two essential aspartyl

Received Sept. 3, 2003; revised Jan. 30, 2004; accepted Jan. 30, 2004.

P.C.W. was supported by National Institutes of Health Grants NS41438 and NS45150. We thank Dr. Joseph Najbauer, Dr. Brett Johnson, and Dr. Jeremy Toyn for helpful discussions and Dr. Margi Goldstein for proofreading of this manuscript.

Correspondence should be addressed to Yu-Wen Li, Bristol-Myers Squibb Company, 5 Research Parkway, 382E, Wallingford, CT 06492. E-mail: yu-wen.li@bms.com.

DOI:10.1523/JNEUROSCI.0092-04.2004

Copyright $\odot 2004$ Society for Neuroscience $\quad$ 0270-6474/04/242942-11\$15.00/0 residues (Wolfe et al., 1999; Kimberly et al., 2000). Also, compounds inhibiting A $\beta$ production photolink to PS at the molecular level (Esler et al., 2000; Li et al., 2000; Seiffert et al., 2000). These inhibitors appear to bind at or affect the putative active site of PS, or both, and to disrupt the $\gamma$-site processing of APP (Li et al., 2000; Kornilova et al., 2003; Tian et al., 2003). The specific and pharmacologically effective binding of the inhibitors to PS provides an opportunity to use them as markers to display the functional or active sites of $\gamma$-secretase in situ.

Previous studies have characterized the distribution of PS mRNA and related protein products in rodent and primate brains by in situ hybridization and immunohistochemistry, indicating significant constitutive expression of PS in the brain (Elder et al., 1996; Lee et al., 1996; Moussaoui et al., 1996; Page et al., 1996; Blanchard et al., 1997; Takami et al., 1997). Other studies show lethal impact of PS knock-out on brain development (Wong et al., 1997; De Strooper et al., 1998). Thus, PS appears to play vital biological roles in the nervous system. It should be noted that PS-1 and PS-2 are large multidomain proteins present in multiple cellular compartments as holoproteins as well as cleaved fragments on activation (Thinakaran et al., 1996; Podlisny et al., 1997; Kamal et al., 2001). Furthermore, functionally, PS is involved in a number of other cellular processes in addition to $\gamma$-site cleavage of APP (De Strooper, 2003). Thus, 
approaches revealing the functional or active site of $\gamma$-secretase in the brain may provide better information for understanding of the neurobiology of this enzyme. We have synthesized potent and specific $\mathrm{A} \beta$-lowering small-molecule $\gamma$-secretase inhibitors (Seiffert et al., 2000). Using radiolabeled $\gamma$-secretase inhibitors, the present study aimed to map the binding sites in developing and mature rodent brains. An additional attempt was made to investigate whether the remarkably dense binding sites existed in the olfactory bulb were related to the presence of neuronal terminals.

\section{Materials and Methods}

Animals and tissue preparation. The embryos of wild-type and PS-1 knock-out mice were used in this study for characterization of the radioligand. The mouse strains were generated according to a previous report (Wong et al., 1997). All embryos were harvested at embryonic day 17 and genotyped using yolk sacs by PCR using primers PS1KO-1 (5' -AGC CAA GAA CGG CAG CAG CA-3'), PS1KO-2 (5'-CTT CCA TGA GCC ATT TGC TAA GTG C-3'), and NEO-AS5 (5'- GGT GGA TGT GGA ATG TGT GCG AGG-3'). The PCR products for the wild-type allele and $\mathrm{PS}^{-1-}$ allele are $\sim 500$ and $250 \mathrm{bp}$, respectively. The PS- $1^{+/+}, \mathrm{PS}-1^{+/-}$, and PS- $1^{-1-}$ embryos $(n=4$ for each genotype $)$ were stored at $-70^{\circ} \mathrm{C}$ before sectioning.

Sprague Dawley rats used in this study were purchased from Charles River Laboratories (Wilmington, MA). Male adult rats (weighting 200$300 \mathrm{gm}$ ) were doubly housed, and neonatal rats were housed with the mother before weaning. The rats were kept in shoebox cages in a colony room maintained at a constant temperature $\left(21-22^{\circ} \mathrm{C}\right)$ and humidity $(50 \pm 10 \%)$. The room was illuminated $12 \mathrm{hr} / \mathrm{d}$ (lights on at 6 A.M.). The rats had ad libitum access to food and water throughout the study. For neonatal rats, the day of birth was referred to as postnatal day $0(\mathrm{P} 0)$, and litters were standardized to eight pups on $\mathrm{P} 0$ with equal numbers of males and females. To characterize the normal distribution and developmental expression of binding sites in the brain, rats were examined at $\mathrm{P} 0(n=8)$, P4 $(n=4), \mathrm{P} 7(n=4), \mathrm{P} 14(n=4), \mathrm{P} 21(n=4), \mathrm{P} 30(n=4), \mathrm{P} 45(n=$ 4 ), and P60 (i.e., the adult; $n=4)$. Equal numbers of male and female rats were used at each time point from P0 to P45. Additional adult $(n=10)$ and P7 $(n=6)$ rats were used in saturation and competition binding assays.

Chemical deafferentation of the olfactory bulb was initiated by nasal infusion of zinc sulfate $\left(\mathrm{ZnSO}_{4}\right)$, using previously established procedures (Herzog and Otto, 1999). Adult male rats $(n=28)$ were anesthetized with isoflurane inhalation. Bilateral intranasal infusion of $50 \mu \mathrm{l}$ of either $\mathrm{ZnSO}_{4}(2 \%)$ or vehicle (sterile saline) was then given using a $1 \mathrm{ml}$ insulin syringe with a blunted and curved dosing needle (22 gauge). At each time point, four $\mathrm{ZnSO}_{4}$-treated and one or two vehicle-treated subjects were used. After nasal treatments, the rats were returned to their home cages for $1,7,14,28$, or $42 \mathrm{~d}$ survival times. All procedures in the present study were approved by the Animal Care and Use Committee of Bristol-Myers Squibb.

After decapitation, brains were removed, frozen immediately in isopentane over dry ice, and then stored at -20 to $-70^{\circ} \mathrm{C}$ until use. For the nasal cavity-infused rats, the forebrain and the nasal structures (septum, cribriform plate, and turbinates) were collected together. Brain sections from normal developing and adult rats were cut coronally or sagittally at $20 \mu \mathrm{m}$ on a cryostat and thaw-mounted consecutively on 10 sets of Superfrost Plus slides (VWR Scientific, West Chester, PA). The olfactory bulb and epithelium from rats receiving nasal infusion were cut together frontally and mounted consecutively on 10 sets of slides. The wild-type and PS- 1 knock-out mouse embryos were cut to sagittal sections, and one of every 20 sections was collected on slides. All slides were air-dried and then stored at $-70^{\circ} \mathrm{C}$ until use.

Compounds and binding autoradiography. Small-molecule $\gamma$-secretase inhibitors, compounds A, C, and D, were synthesized by the Chemical and Physical Sciences Department of Bristol-Myers Squibb. Another compound, L-685,458, which is a transition state analog of the $\gamma$-secretase inhibitor, was purchased from Peptide Institute, Inc (Osaka, Japan; catalog \#4394-v). Compound C and a photolinkable derivative of $\mathrm{L}-685,458$ have been previously shown to cross-link to the $\mathrm{N}$ - and
C-terminal fragments of PS, which are considered the putative active sites of the enzyme ( $\mathrm{Li}$ et al., 2000; Seiffert et al., 2000). The chemical structures of these compounds are shown in Figure 1. Tritium labeling of compound $\mathrm{D}(83.4 \mathrm{Ci} / \mathrm{mm})$, the principal radioligand used in this study, is described below. To a solution of compound $1(3.5 \mathrm{mg})$ in methanol $(1.0 \mathrm{ml})$ was added $5 \%$ palladium on alumina $(1.5 \mathrm{mg})$. The mixture was stirred under 40 psi carrier-free tritium gas for $2 \mathrm{hr}$ (performed at PerkinElmer Life Sciences, Norwalk, CT). Labile tritium was removed by evaporation with methanol. The crude product $(160 \mathrm{mCi}, 89 \%$ radiochemical purity) was purified on a Zorbax SB-C18 column $[250 \times 9.4$ $\mathrm{mm}, 60 \%$ methanol in water containing $0.05 \%$ trifluoroacetic acid (TFA)]. Fractions containing the product were combined, and solvents removed by rotary evaporation and redissolved in ethanol to yield an ethanolic solution of compound $2(130 \mathrm{mCi})$. The radiochemcial purity by HPLC analysis (Zorbax SB-C18; A, 0.05\% TFA in water; B, 0.05\% TFA in methanol; $40 \%$ B for 5 min, linear gradient from $40-95 \%$ B in 15 min, hold $95 \%$ B for $10 \mathrm{~min}$, flow rate, $1 \mathrm{ml} / \mathrm{min}$ ) was found to be $>99 \%$. Specific activity by mass spectroscopy (direct chemical ionization, ammonia) was $86 \mathrm{Ci} / \mathrm{mm} .{ }^{3} \mathrm{H}$ nuclear magnetic resonance $(320 \mathrm{MHz})$ yielded multiplets at $\delta 0.896(70 \%)$ of 1.22 and $1.36(30 \%)$.

The binding procedure on brain sections was adapted from that conducted on a membrane of a human monocytic cell line, THP-1, described previously (Seiffert et al., 2000). One set of slides of brain and embryo sections and two sets (sets 1 and 6) of the olfactory bulb sections from nasal cavity-infused rats were processed for ligand binding. One additional set of adjacent slides was used for determining nonspecific binding. Sections were warmed to room temperature before incubation with ligands. In each experiment, slides from two or more brains at each postnatal age or survival time were processed together under identical conditions. Briefly, the slides were preincubated for $10 \mathrm{~min}$ in $50 \mathrm{~mm}$ HEPES buffer, $\mathrm{pH} 7.4$, transferred to the same buffer containing 3.8-4.6 nм $\left[{ }^{3} \mathrm{H}\right]$ compound $\mathrm{D}$, and incubated for $60 \mathrm{~min}$ at room temperature. The adjacent sections for determining nonspecific binding were incubated in the same buffer containing $\left[{ }^{3} \mathrm{H}\right]$ compound $\mathrm{D}$ but included unlabeled compounds at $0.5 \mu \mathrm{M}$ (see Fig. $3 B, C$ ). After the incubation with the radiolabeled ligand, the slides were washed with ice-cold PBS, $\mathrm{pH} 7.2$, three times for a total of $10 \mathrm{~min}$. Saturation and competition binding assays were also performed on brain sections following the same binding procedure as described above, except that groups of sections were incubated in buffers with a series concentrations of either the radioligand $\left[{ }^{3} \mathrm{H}\right]$ compound $\mathrm{D}$ and one of the unlabeled ligands, compound $\mathrm{A}$ or D at $0.5 \mu \mathrm{M}$ (saturation), or with $5 \mathrm{nM}\left[{ }^{3} \mathrm{H}\right]$ compound D plus one of the unlabeled ligands at multiple concentrations (competition). After incubation with ligands, the slides were briefly dipped in ice-cold distilled water before they were dried by a stream of cold air. Next, the slides, together with ${ }^{3} \mathrm{H}$ microscales (Amersham Biosciences, Arlington Heights, IL), were placed under tritium-sensitive phosphor storage screens and exposed in the dark for 7 and $14 \mathrm{~d}$ before the screens were scanned with a Cyclone phosphor scanner (Packard, Meridian, CT). The shorter exposure time was used for quantitative developmental observation of the binding sites because the binding in the early postnatal brains was generally intense. Accordingly, the longer exposure time was chosen for better visualization of binding sites in the adult brains. The slides were finally stained with cresyl violet for verification of cytoarchitecture.

Image and data analysis. Storage phosphor images were acquired with a personal computer-controlled Cyclone phosphor scanner using OptiQuant acquisition and analysis software (Packard). Optic densities (expressed as digital light units per square millimeter) over areas of interest and the ${ }^{3} \mathrm{H}$ standards were measured. Readings of binding values in a defined region were calculated by subtracting the value of the nonspecific binding from that of the total binding measured in the same region. The value of specific binding was then converted to femtomoles per milligram of tissue equivalent, when appropriate, according to a curve generated from optic density readings of the ${ }^{3} \mathrm{H}$ standards in each experiment and the specific radioactivity of the radioligand. Saturation data were fit with a hyperbola model to estimate the apparent $K_{\mathrm{d}}$ and $B_{\max }$ using nonlinear regression curve-fitting programs in Prism (GraphPad, San Diego, CA). Competition data were fit with a sigmoid dose-response equation with the same program to estimate $\mathrm{IC}_{50}$. Data were expressed as mean $\pm \mathrm{SEM}$ 

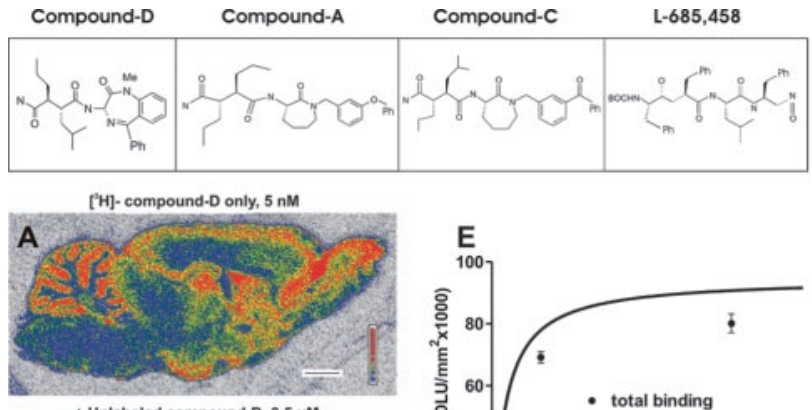

+ Unlabeled compound-D, 0.5 uM

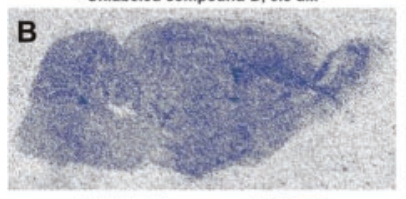

+ Unlabeled compound-C, 0.5 uM

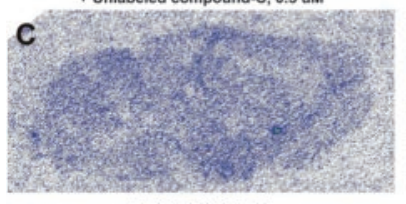

$+\mathrm{L}-685,458,0.5 \mathrm{uM}$
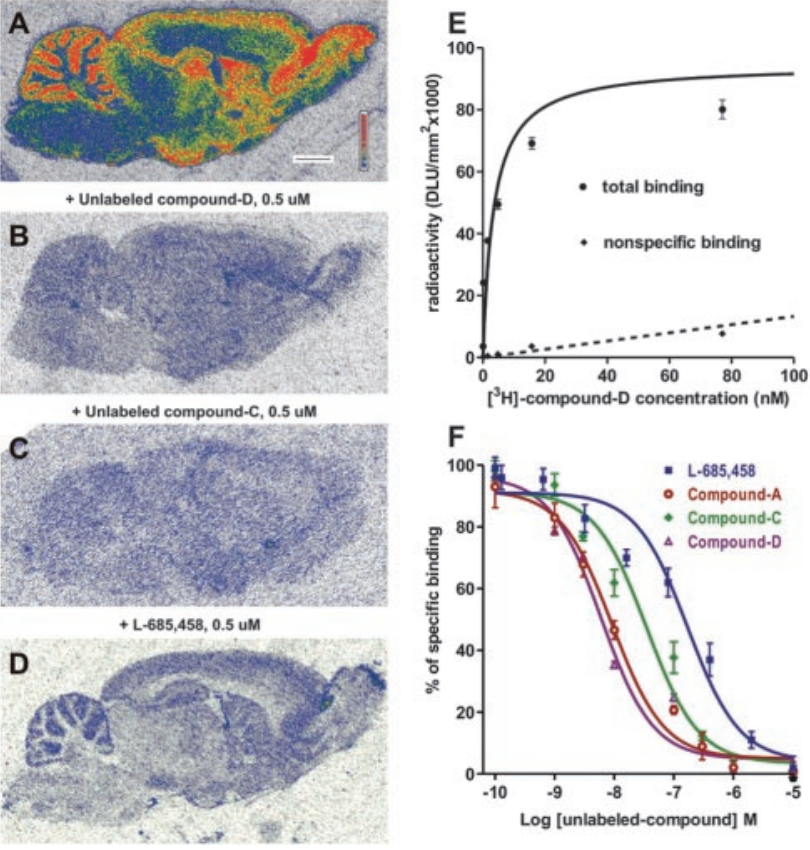

Figure 1. Chemical structures (top) of the $\gamma$-secretase inhibitors used in the present study and characterization of $\left[{ }^{3} \mathrm{H}\right]$ compound $\mathrm{D}$ binding in adult rat brain sections $(A-F)$. A, Total binding yielded with $5 \mathrm{~nm}\left[{ }^{3} \mathrm{H}\right]$ compound $D$, which is greatly inhibited in the presence of $500 \mathrm{~nm}$ cold compound $D(B), C(C)$, or L-685,458. E, F, Curve-fitting graphs showing that $\left[{ }^{3} \mathrm{H}\right]$ compound $D$ binding in a brain section is saturatable $(D)$, and the inhibition by unlabeled compounds is concentration-dependent $(E)$. The competition $\mathrm{IC}_{50}$ values for the unlabeled inhibitors are as follows: compound A, $9.6 \mathrm{~nm}$; compound C, $25 \mathrm{~nm}$; compound D, $3.3 \mathrm{~nm}$; and L-685,458, $120 \mathrm{~nm}$. DLU, Digital light units. Scale bar: $A-D, 4 \mathrm{~mm}$.

and subjected to ANOVA, where appropriate, followed by individual mean comparisons using Dunnett $t$ test. The significance level was set at $p<0.05$. All pseudocolor representations of storage phosphor images were prepared using OptiQuant-3.1 (Packard) and CorelDRAW-10 (Corel Corp., Ottawa, Ontario, Canada) image software. The color assignments representing levels of binding intensity in the figures are indicated with inserted color bars.

\section{Results}

\section{Characterization of binding in brain sections}

Only $\left[{ }^{3} \mathrm{H}\right]$ compound D was chosen as the radioligand for brain section autoradiography in the current study because pilot experiments indicated that the specific binding in brain sections of other ${ }^{3} \mathrm{H}$-labeled small-molecule $\gamma$-secretase inhibitors was low ( $<50 \%$ of total binding) because of high background (results not shown). Figure $1 A$ illustrates the intensity and overall brain distribution pattern of total $\left[{ }^{3} \mathrm{H}\right]$ compound D binding at a $5 \mathrm{~nm}$ concentration. This binding was greatly inhibited in presence of $0.5 \mu \mathrm{M}$ unlabeled compounds $\mathrm{D}$ (used to define the nonspecific binding; Fig. $1 B$ ), C (Fig. 1C), L-685,458 (Fig. $1 D$ ), and A (results not shown). The binding of $\left[{ }^{3} \mathrm{H}\right]$ compound $\mathrm{D}$ was concentration-dependent and saturatable, with an apparent $K_{\mathrm{d}}$ of $3.2 \mathrm{nM}$ according to saturation binding assays (Fig. $1 E$ ). Competition binding assays indicated that $\left[{ }^{3} \mathrm{H}\right]$ compound $\mathrm{D}$ binding was completely displaceable by each of the unlabeled compounds (Fig. $1 \mathrm{~F}$ ). The estimated $\mathrm{IC}_{50}$ values of the unlabeled ligands were as follows: compound A, $9.6 \mathrm{nM}$; com- pound C, $25 \mathrm{~nm}$; compound D, $3.3 \mathrm{~nm}$; and L-685,458, $120 \mathrm{~nm}$. The rank order of binding affinity of these compounds appeared to be correlated to their $\mathrm{A} \beta$ inhibition capability in cell-based systems (Seiffert et al., 2000; Beher et al., 2001).

\section{Effect of PS-1 knock-out on $\left[{ }^{3} \mathrm{H}\right]$ compound D binding}

To further address the relevance of ${ }^{3} \mathrm{H}$-labeled compound $\mathrm{D}$ binding to PS expression, we compared the binding density of $\left[{ }^{3} \mathrm{H}\right]$ compound D in the brain and periphery of PS- $1^{+/+}$, PS$1^{+/-}$, and PS- $1^{-1-}$ embryos. Because the PS- $1^{-1-}$ mice are not viable postnatally, embryos were collected at embryonic day 17 for examination of the binding sites. The genotypes of the embryos were determined by PCR. Gel analysis of the PCR products showed a single $500 \mathrm{bp}$ band in the wild type, a single $250 \mathrm{bp}$ band in the PS-1 $1^{-l-}$ embryos, and both bands for the PS- $1^{+/-}$embryos (Fig. 2F). Quantification of the abundance of binding sites in the brain was represented by measuring binding density in the dorsal wall of the telencephalic vesicle and that for the peripheral tissues in the liver and the wall of embryonic gastrointestinal ducts. An overall reduction of binding sites was readily evident across the body of the PS- $1^{+/-}$embryos relative to wild type (Fig. $2 A, B)$. A further decrease of binding sites was noted in the PS$1^{-l-}$ embryos compared with the wild-type and PS- $1^{+1-}$ embryos (Fig. $2 A-C$ ). Nonspecific binding was minimal and similar in the embryos of all three genotypes (Fig. 2D). Quantitative data indicated that the reduction of binding density relative to the wild type was $\sim 50$ and $80 \%$ in PS- $1^{+/-}$and PS- $1^{-1-}$ embryos, respectively. The degree of reduction was similar for the brain and peripheral tissues (Fig. 2E).

\section{Distribution of binding sites in the adult brain}

In general, specific $\left[{ }^{3} \mathrm{H}\right]$ compound D binding sites were widely but differentially distributed in the adult rat brain. A large amount of radiolabeling was localized to the cerebrum and cerebellum. In addition, selective lamina or areas of the olfactory bulb, striatum, thalamus, and midbrain exhibited dense binding. The radiolabeling was low in most low brainstem regions and minimal in the white matter and large nerve fiber bundles of the brain.

\section{Olfactory bulb}

In the olfactory bulb, the binding sites were detectable in most layers except the core region corresponding to the subependymal zone (Figs. 3A, 4A,B). The binding in the region corresponding to the granule cell and mitral cell layers was moderately strong. The glomerular layer displayed strikingly dense binding that appeared to be located predominantly within individual glomeruli but not in the interglomerular regions (Fig. 4A,B). The olfactory nerve layer also exhibited a low level of labeling.

\section{Septum and striatum}

The binding sites in the septum were primarily localized to the lateral nucleus (Fig. 3C). The medial septal nucleus and the nucleus of the diagonal band of Broca showed few binding sites (Fig. $3 C, D)$. Radiolabeling was detectable throughout the striatum, but the ventrolateral division demonstrated apparently stronger labeling compared with the dorsomedial division (Fig. 3C,D). The ventral pallidum also expressed some binding sites at a level similar to that in the ventrolateral striatum (Fig. 3C).

\section{Bed nucleus of the stria terminalis and amygdaloid complex}

Densely packed binding was present in all subdivisions of the bed nucleus of the stria terminalis (BNST) ventrorostral to the anterior horn of lateral ventricle (Fig. $3 C, D$ ). The binding sites in the 
PS- $1+/+$

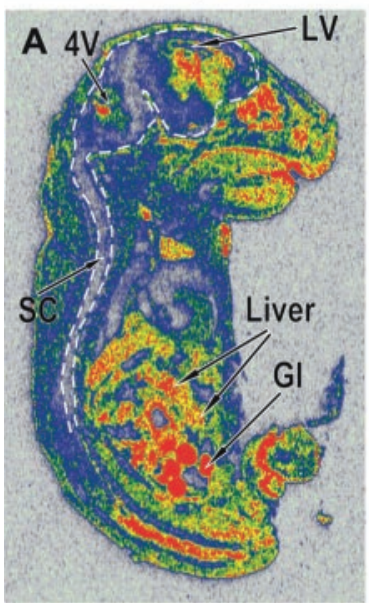

Non-specific

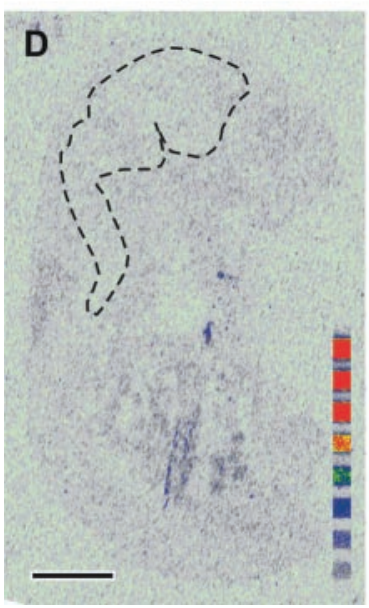

PS-1+/-
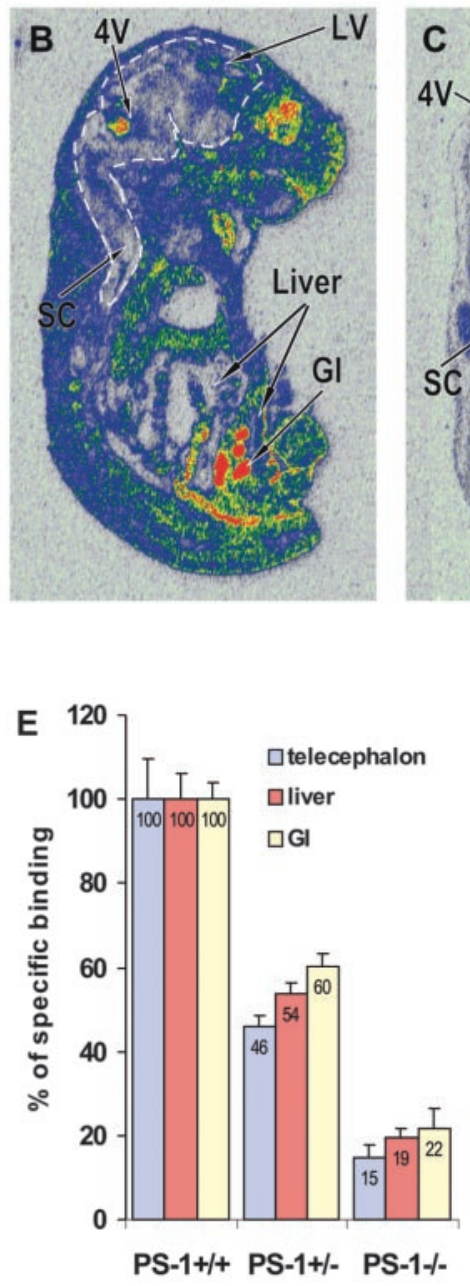

PS-1-/-

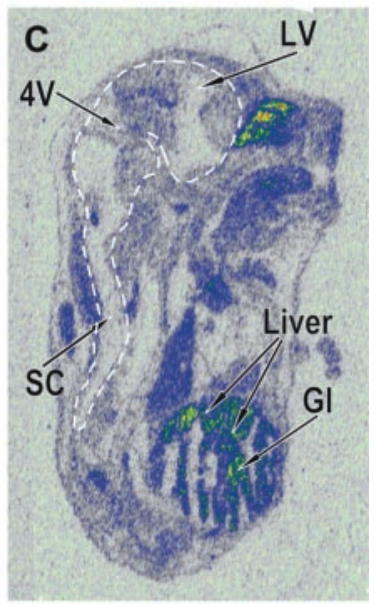

Marker +/- WT -/-

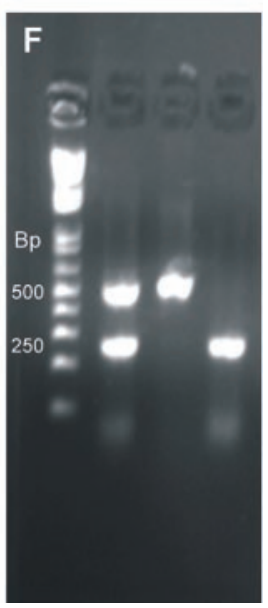

Figure 2. Correlation of $\left[{ }^{3} \mathrm{H}\right]$ compound D binding sites and PS-1 gene expression in mouse embryos. $A-C$, Representative parasagittal sections from wild-type (PS-1 ${ }^{+/+}$), heterozygous (PS-1 $1^{+/-}$), and homozygous (PS-1 ${ }^{-1-}$ ) PS-1 knock-out embryos ( $n=4$ for each genotype). Note the global reduction of binding sites in the heterozygous $(B)$ and homozygous ( $C$ ) relative to the wild type $(A)$. D, Level of nonspecific binding as a control for these embryo sections. $E$, Quantification of binding densities measured from the dorsal wall of the telencephalic vesicle (telencephalon), the liver, and the wall of the rudimentary gastrointestinal duct (GI). The readings of binding density of the same region were normalized to those from the wild-type embryos. Note that there are $\sim 50$ and $80 \%$ losses of binding sites in the PS $-1^{+1-}$ and PS- $1^{-1-}$ embryos, respectively, relative to the wild type in the representative central and peripheral regions. $F$, Representative gel analysis of the PCR product of the three genotypes of embryos. The products of the wild-type (WT) allele and the PS-1 ${ }^{-1-}$ allele are $\sim 500$ and $250 \mathrm{bp}$, respectively, whereas those for PS-1 ${ }^{+1-}$ allele contain both. The broken line approximately outlines the border of the brain and spinal cord (SC). LV, Lateral ventricle; $4 \mathrm{~V}$, fourth ventricle. Scale bar, $250 \mu \mathrm{m}$.

BNST continued to the preoptic region of the hypothalamus. In the amygdaloid complex, the binding sites were spread throughout all its subdivisions or nuclei (Fig. $3 E, F$ ). The overall density was similar in different amygdaloid subnuclei at a level comparable with that in the neighboring ventrolateral striatum or cerebral cortex (Fig. 3D-F). Dorsolateral to the amygdaloid complex, the endopiriform nuclei contained a high level of binding sites.

\section{Neocortex}

The binding sites were distributed in all areas of the neocortex in the adult brain (Fig. 3B-H), and appeared to be localized exclusively to the gray matter. The overall density of binding sites appeared to be similar in the cortex of the frontal, parietal, and occipital lobes. Also, a similar laminar distribution pattern of binding sites was noted in these cortical regions. A gradient of high to low binding density was present from the superficial to deep cortical layers (Fig. $3 C-G$ ). By overlapping the binding and Nissl stain images of the same section, the densely labeled superficial cortical layers in the neocortex corresponded to layers II-IV (Fig. 4C,D).

\section{Olfactory and limbic cortices}

A high density of the binding sites was also seen in the olfactory and limbic cortices, including the orbital, cingulate, insular, piriform, and entorhinal areas (Fig. $3 B-$ $G)$. The overall intensity of binding sites over these areas appeared to be mostly similar to that in the neocortex. The binding sites in the olfactory and limbic cortical areas seemed to be mostly localized to layers II and III.

\section{Hippocampal formation}

The pyramidal cell layer demonstrated the highest density of the binding sites (Figs. $3 F, G, 4 E, F)$. The labeling in this layer was apparently stronger in the CA 3 than CA1 and CA2 regions (Fig. $4 E, F$ ). In the dentate gyrus, higher binding was present in the hilus than the granule cell and molecular layers. Because of the dense binding in the CA3 pyramidal cell layer and the hilus, a pair of bands with strong radioactive intensity was distinctly displayed in the hippocampal region in each hemisphere at the midbrain level (Fig. 3G).

\section{Thalamus}

Overall, the thalamus exhibited low binding density compared with the neighboring cerebral cortex and hippocampal formation (Fig. 3E,F). The medial thalamic region located near the midline demonstrated the highest binding among the thalamic nuclei. Relatively dense binding sites were present in the medial (Fig. 3G) and lateral (results not shown) geniculate nuclei. The binding sites in the dorsal thalamic nuclei were low, and very little binding was observed in the ventral and posterior thalamic nuclei.

\section{Hypothalamus}

The areas of hypothalamus with dense binding were generally those in close proximity to the third ventricle. Thus, at the level of the optic chiasm, the anterior and medial preoptic nuclei were strongly labeled, whereas the lateral preoptic area exhibited much less binding (Fig. 3D). Likewise, the medial hypothalamic areas encompassing the paraventricular, anterior, dorsomedial, and ventromedial hypothalamic nuclei were moderately to strongly labeled, whereas the lateral hypothalamic region displayed sparse binding sites (Fig. 3E, G). The pituitary body contained an extremely high density of binding both in the posterior and anterior lobes (Fig. 3C,D).

\section{Midbrain and brainstem}

Only a limited number of areas exhibited strong binding in the brainstem. The regions with high or moderate binding density included the superior and inferior colliculi, the central gray, the 


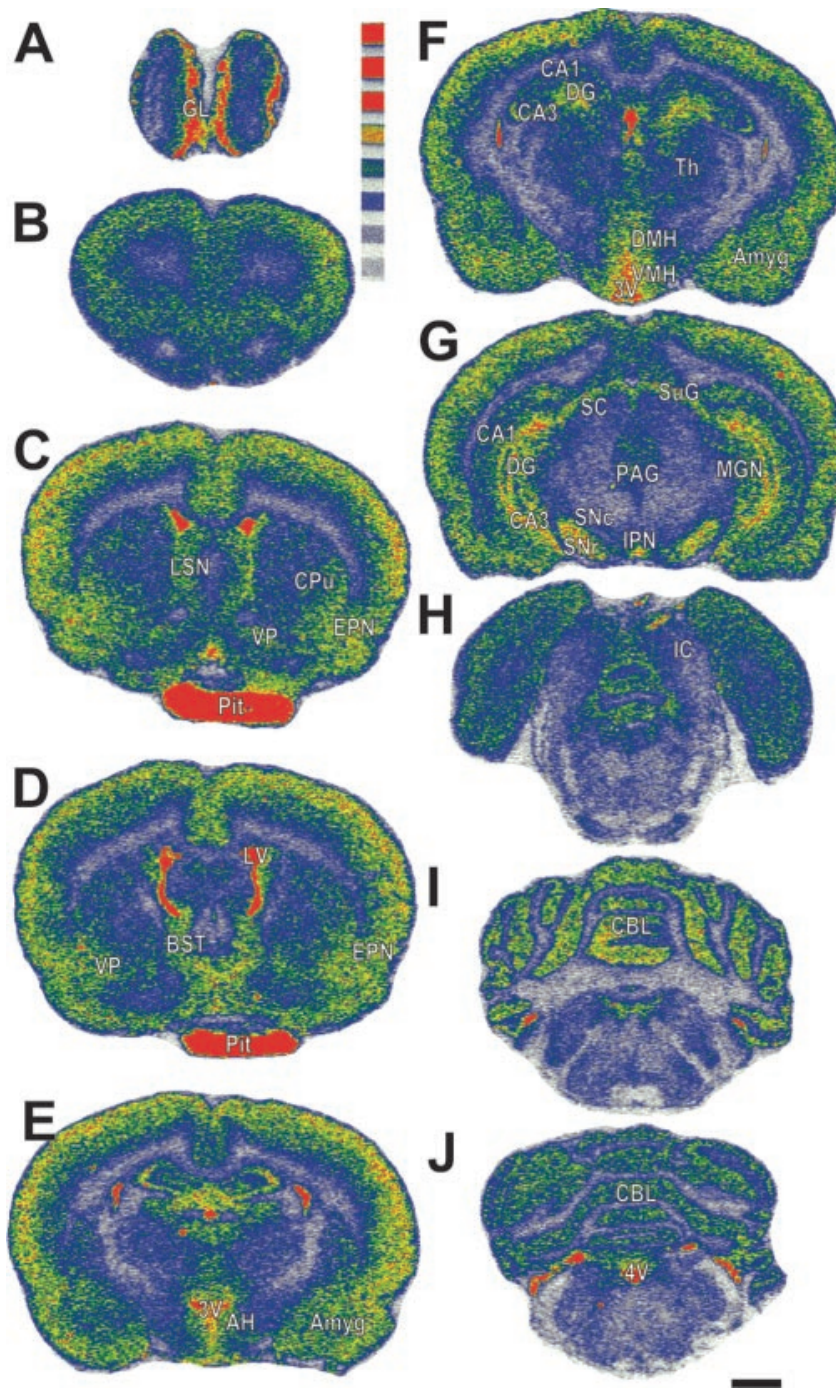

Figure 3. Distribution of $\left[{ }^{3} \mathrm{H}\right]$ compound $\mathrm{D}$ binding sites in the adult rat brain. Binding sites are mostly localized to the forebrain structures and the cerebellum. For details, see Results. GL, Glomerular layer; $\mathrm{CPu}$, caudate putamen; LSN, lateral septal nucleus; VP, ventral pallidum; EPN, endopiriform nucleus; Pit, pituitary; BST, bed nucleus of the stria terminalis; $3 \mathrm{~V}, 4 \mathrm{~V}$, third and fourth ventricles; $\mathrm{AH}$, anterior hypothalamic nuclei; Amyg, amygdaloid complex; Th, thalamus; $\mathrm{DMH}, \mathrm{VMH}$, dorsomedial and ventromedial hypothalamic nuclei; SC, superior colliculus; SuG, superficial gray layer; DG, dentate gyrus; $C A 1, C A 3, C A 1$ and $C A 3$ sectors of hippocampus; PAG, periaqueductal gray; IPN, interpeduncular nucleus; IC, inferior colliculus; $C B L$, cerebellum. Scale bar, $1 \mathrm{~mm}$.

substantia nigra, and the interpeduncular nucleus. The dense binding sites in the superior colliculus appeared to be restricted to the superficial gray layer (Fig. $3 G$ ). The binding sites in the inferior colliculus were mainly present in the dorsomedial region near the midline (Fig. $3 H$ ). The distribution pattern of the binding sites in the substantia nigra was of great interest because the sites were only localized to the cell-sparse pars reticulata but not the cell-dense pars compacta (Figs. 3G, 5A,B). Remarkably sparse binding sites were found along the entire extent of the pons and medulla oblongata (Fig. $3 H-J$ ). The major neural tracts in the brainstem rarely displayed binding sites.

\section{Cerebellum}

The cerebellum expressed a great amount of binding sites (Fig. $3 I, J)$. Similar to the cerebrum, the binding sites in the cerebellum were limited to the cortex. The binding sites in the molecular
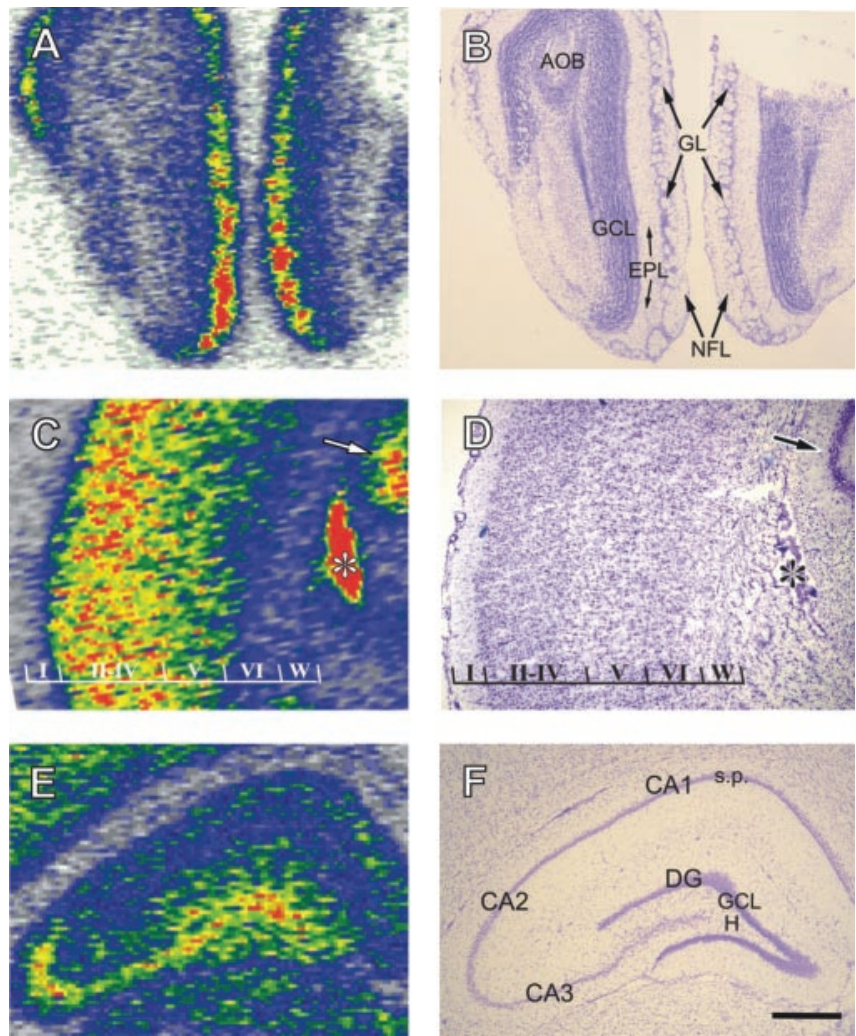

Figure 4. Laminar distribution of binding sites in the olfactory bulb $(A, B)$, neocortex $(C, D)$, and hippocampal formation $(E, F)$. The left and right panels are corresponding images of same region illustrating the binding sites and histology (Nissl stain), respectively. Note the extremely dense binding sites within individual glomerulus in the olfactory bulb $(A, B)$, the predominant localization of binding sites in layers II-IV in the parietal cortex $(C, D)$, and the stronger labeling in the $\mathrm{CA} 3$ and hilus $(\mathrm{H})$ than $\mathrm{CA} 1$ and granule cell layer $(\mathrm{GCL})$ in the hippocampal formation $(E$, $F)$. Arrows, asterisks in C, D, CA3 pyramidal cell layer and choroid plexus, respectively. GL, Glomerular layer; EPL, external plexiform layer; NFL, nerve fiber layer; s.p., stratum pyramidale; DG, dentate gyrus; I-VI, cortical layers; W, white matter. Scale bar, $200 \mu \mathrm{m}$.

layer appeared to be even denser than those in the Purkinje cell and granule cell layers (Fig. 5C,D). This cortical distribution of binding was homogeneous across the entire rostrocaudal and mediolateral extents of the cerebellum (Fig. $1 B$ ). A few binding sites were detectable in the deep cerebellar nuclei (Fig. 5C,D).

\section{Ventricular system}

Extremely dense binding sites were seen in the lateral and fourth ventricular areas where the choroid plexuses are located (Figs. $3 C-F, I, J, 4 C, D, 5 C, D)$.

\section{Quantification of binding site density in the adult brain}

For a more convenient cross-region comparison, we quantified the density of binding sites in various brain areas. For a given brain area, at least two coronal section levels (200 $\mu \mathrm{m}$ interval) of both hemispheres were sampled, and the value of the specific binding in the area, expressed as femtomoles per milligram of tissue equivalent, was averaged from four brains (Table 1). The choroid plexus ( $467.8 \mathrm{fmol} / \mathrm{mg})$, pituitary $(360.4 \mathrm{fmol} / \mathrm{mg})$, and glomerular layer of the olfactory bulb $(383.2 \mathrm{fmol} / \mathrm{mg})$ appeared to have the highest binding density, followed by the dentate gyrus, substantia nigra pars reticulata, and cerebellar cortex, with density values of $170-190 \mathrm{fmol} / \mathrm{mg}$. Other brain regions, including the mitral and granule cell layer of the olfactory bulb, olfactory and limbic cortex, neocortex, amygdaloid nuclei, hippocampal formation, medial hypothalamic area, superficial gray layer of 

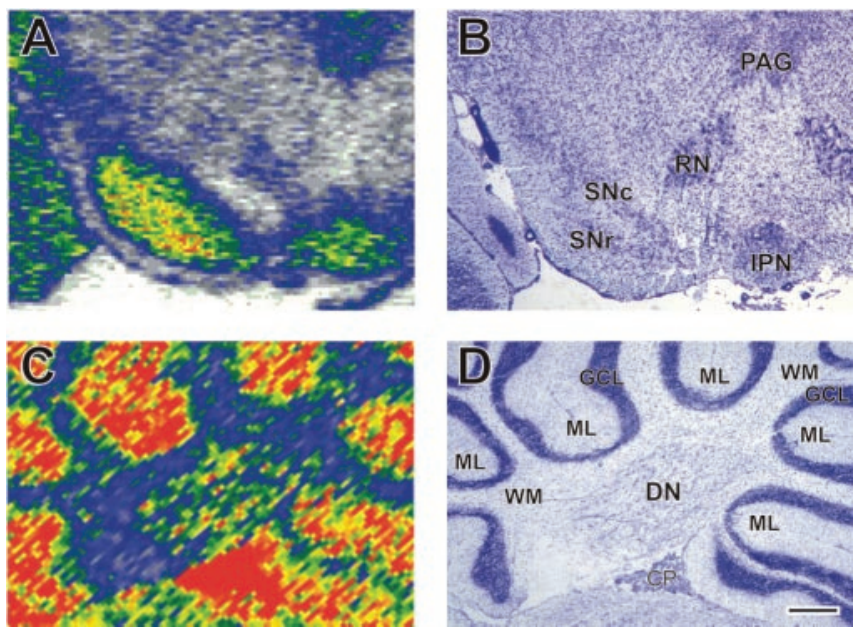

Figure 5. Distribution of binding sites in the substantia nigra $(S N ; A, B)$ and cerebellum $(C, D)$. In the $\mathrm{SN}(A, B)$, binding sites are exclusively present in the $\mathrm{SNr}$ rather than the $\mathrm{SNc}$. Binding sites in the cerebellar cortex are more densely packed in the molecular layer (ML) than the Purkinje cell ( $D$, arrows) and granule cell (GCL) layers (C, D). PAG, Periaquious gray; RN, red nucleus; IPN, interpeduncular nucleus; DN, dentate nucleus. Scale bar: $A, B, 200 \mu \mathrm{m} ; C, D, 500 \mu \mathrm{m}$.

the superior colliculus, and interpeduncular nucleus, were moderately labeled $(120-150 \mathrm{fmol} / \mathrm{mg})$. In the hippocampal formation, CA3 (150 fmol/mg) and dentate gyrus (175 fmol/mg) were more heavily labeled than CA1 $(117 \mathrm{fmol} / \mathrm{mg})$.

\section{Postnatal change in binding density}

The overall binding density across the brain exhibited significant developmental changes in postnatal rats. The density was markedly higher in the early postnatal brains than in the young and adult rat brains in virtually all regions examined (Fig. 6). There was no detectable difference between male and female rats. The highest density of binding sites appeared around the end of the first postnatal week (Fig. $6 \mathrm{~B}, \mathrm{C}$ ). To gain an overview of change in the binding density with age, a quantitative analysis was conducted in four brain regions that showed relatively rich binding sites in the adult (Table 1). These were the neocortex (frontoparietal area), hippocampal formation, cerebellum, and substantia nigra (pars reticulata) (Fig. 7). The average value of binding density at different ages was normalized to that in the adult (P60) in the same region.

As shown in Figure 7, albeit different in the initial level of binding site expression among the regions tested relative to the adult, the binding density in all these regions increased during the first postnatal week and reached the maximum at $\sim \mathrm{P} 7$ (neocortex and hippocampus) to P14 (substantia nigra and cerebellum). A swift decrease in the binding density occurred during the third postnatal week, followed by a further gradual decline in the next 2 weeks. The adult level of binding density was established by P45.

We further assessed whether the high binding density in the early postnatal brains represented an age-dependent change in the population of binding sites or in the binding affinity. A saturation binding experiment was performed on sections from the P7 and adult brains (Fig. 8). The results showed that the $B_{\max }$ values were different in different brain regions in both the $\mathrm{P} 7$ and adult brains. In the same brain region, the $B_{\max }$ value was higher at P7 than adult. In contrast, the $K_{\mathrm{d}}$ did not exhibit a difference between the P7 and adult brains. For example, the estimated $B_{\max }$ values in the hippocampus $(612 \mathrm{fmol} / \mathrm{mg}$ ) and frontoparietal cortex ( $421 \mathrm{fmol} / \mathrm{mg})$ at P7 were significantly higher than those in the same regions of the adult $(320 \mathrm{fmol} / \mathrm{mg}$ for hippocampal CA3
Table 1. Numerical density (mean \pm SEM) of specific $\left[{ }^{3} \mathrm{H}\right]$ compound-D binding sites in different brain areas of adult rats $(n=4)$

\begin{tabular}{lc}
\hline Brain area & Density \\
\hline Olfactory bulb & \\
$\quad$ Glomerular layer & $383.3 \pm 16.0$ \\
$\quad$ Granule cell and mitral cell layers & $130.4 \pm 11.9$ \\
Septum (lateral nucleus) & $123.1 \pm 11.8$ \\
Striatum & $93.3 \pm 13.4$ \\
Cerebral cortex & \\
$\quad$ Frontal & $137.1 \pm 11.4$ \\
Parietal & $133.6 \pm 7.7$ \\
Piriform/entorhinal & $150.0 \pm 9.9$ \\
Occipital & $137.5 \pm 9.2$ \\
Hippocampal formation & \\
$\quad$ CA1 (stratum pyramidale) & $117.1 \pm 9.9$ \\
$\quad$ CA3 (stratum pyramidale) & $150.3 \pm 11.6$ \\
Dentate gyrus (granular cell layer and & \\
hilus) & $175.2 \pm 10.8$ \\
Amygdaloid complex & $135.8 \pm 6.1$ \\
Thalamus & \\
$\quad$ Medial nucleus & $123.2 \pm 5.3$ \\
Lateral nucleus & $102.1 \pm 12.0$ \\
Ventral and posterior nucleus & $102.7 \pm 11.1$ \\
Medial geniculate nucleus & $99.5 \pm 6.4$ \\
Lateral geniculate nucleus & $78.3 \pm 7.1$ \\
Hypothalamus & \\
Paraventricular nucleus & $134.6 \pm 7.4$ \\
Anterior nucleus & $123.1 \pm 11.3$ \\
Lateral nucleus & $92.4 \pm 11.8$ \\
Dorsomedial nucleus & $143.0 \pm 6.4$ \\
Ventromedial nucleus & $152.3 \pm 5.8$ \\
Brainstem & \\
$\quad$ Superior colliculus & $141.6 \pm 11.4$ \\
Inferior colliculus & $83.2 \pm 15.4$ \\
Central gray & $122.4 \pm 8.0$ \\
Substantia nigra, reticular & $184.7 \pm 12.9$ \\
Interpeduncular nucleus & $128.9 \pm 14.9$ \\
Superior olivery nucleus & $60.3 \pm 15.6$ \\
Trigeminal nucleus & $360.4 \pm 9.1 \pm 8.0$ \\
Cerebellar cortex & $467.8 \pm 33.3$ \\
Pituitary & \\
Choroid plexus & \\
\hline & \\
&
\end{tabular}

and $304 \mathrm{fmol} / \mathrm{mg}$ for cortex). On the other hand, the $K_{\mathrm{d}}$ values for the hippocampus and neocortex were essentially the same at P7 and adult (3.1 vs 3.2 for hippocampus and 3.2 vs 2.8 for cortex).

\section{Postnatal change in binding pattern}

The major difference in the distribution pattern between the immature and mature brains was that the binding sites in the early postnatal brains were diffusely distributed, whereas those in the young and adult brains were differentially expressed (Figs. 3, 6). In the brain structures with a high density of binding sites in the adult, there was no distinctive regional or laminar pattern in the early postnatal brains, whereas in the brain regions with a low level of binding sites in the adult, considerably dense binding sites were frequently detected in the immature brain. For simplicity, we focus our description on the binding pattern at P7.

The laminar distribution of binding sites in the olfactory bulb at P7 appeared similar to that in the adult (Fig. 9A). However, binding sites were present in the entire nerve fiber layer at almost the same density as that in the glomeruli. This was somewhat different from the pattern in the adult bulbs, in which the labeling in the nerve fiber layer was less heavy than that in the glomeruli (Figs. $3 A, 4 A$ ). In the septum and striatum, dense binding sites 

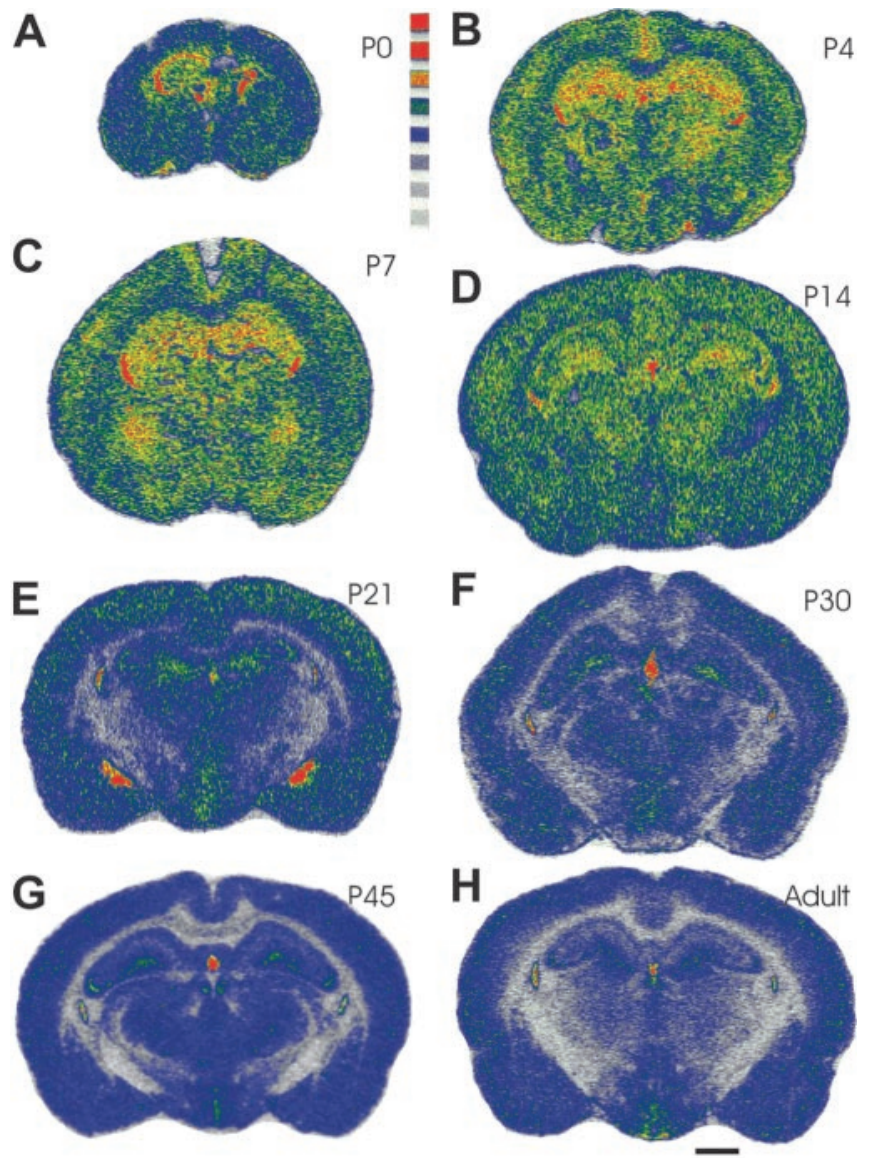

Figure 6. Autoradiograms of sections from comparable brain levels at different postnatal ages (indicated at the top right corner) showing the overall change in density and distribution pattern of $\left[{ }^{3} \mathrm{H}\right]$ compound $\mathrm{D}$ binding sites in the developing rat brain. Note the diffuse and strong radiolabeling across the brain in the first two postnatal weeks $(A-D)$ compared with later stages $(E-H)$. Scale bar, $1 \mathrm{~mm}$.

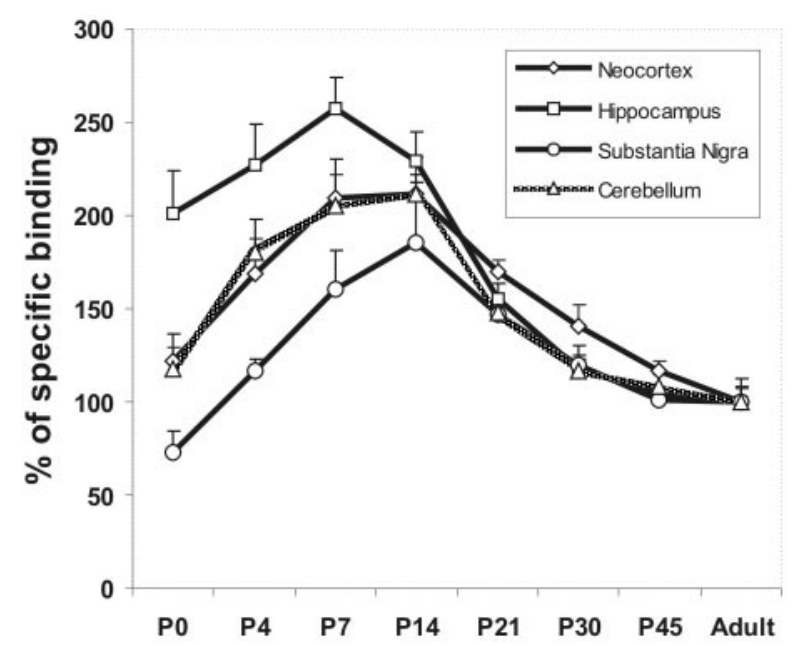

Figure 7. Quantification of binding site density in representative brain areas of the postnatal rats ( $n=4$ at each age). Densities at each age are normalized to adult values. Note that in all four analyzed regions, the binding density peaks during P7-P14 by $150-250 \%$ of the adult levels.

were found in all subdivisions of these structures at virtually the same intensity (Fig. 9B,C).

In the cerebral cortex, binding sites were localized throughout all cortical regions with a similar level of density in the P7 brain

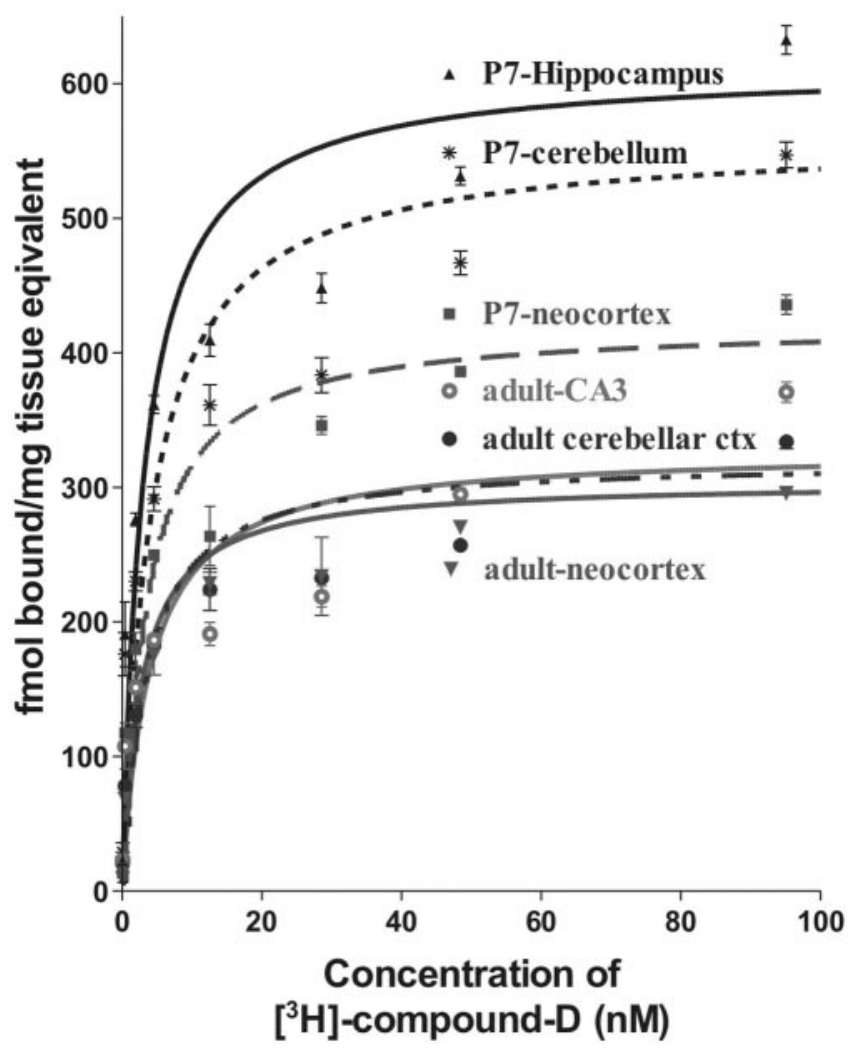

Figure 8. Saturation curves of $\left[{ }^{3} \mathrm{H}\right]$ compound $\mathrm{D}$ binding sites in the $\mathrm{P7}(n=3)$ and adult $(n=3)$ rat brains. The estimated values (mean \pm SEM) of $B_{\max }$ and $K_{\mathrm{d}}$ for different brain regions are, respectively, as follows: $P 7$ hippocampal formation, $612 \pm 54 \mathrm{fmol} / \mathrm{mg}$ and $3.1 \pm$ $1.5 \mathrm{~nm} ; \mathrm{P} 7$ cerebellum, $558 \pm 57 \mathrm{fmol} / \mathrm{mg}$ and $4.2 \pm 2.1 \mathrm{~nm} ; \mathrm{P} 7$ frontoparietal cortex, $421 \pm 28$ $\mathrm{fmol} / \mathrm{mg}$ and $3.2 \pm 1.2 \mathrm{~nm}$; adult cerebellar cortex, $327 \pm 29 \mathrm{fmol} / \mathrm{mg}$ and $3.9 \pm 1.8 \mathrm{~nm}$; adult hippocampal CA3 region, $320 \pm 32 \mathrm{fmol} / \mathrm{mg}$ and $3.2 \pm 1.7 \mathrm{~nm}$; and adult frontoparietal cortex, $304 \pm 21 \mathrm{fmol} / \mathrm{mg}$ and $2.8 \pm 1.1 \mathrm{~nm}$.

(Fig. 9B-E). Low levels of binding sites appeared to be present in the developing white matter. The binding sites in the hippocampal formation appeared homogeneous in all layers of the hippocampus and the dentate gyrus in the first postnatal week (Fig. $6 A-C)$. By P7, the binding sites in the hippocampus became mostly associated with the pyramidal cell layer (Fig. 6C). However, the difference in binding density between CA1 and CA3 seen in the adult brain was not clear until P21 (Figs. $4 E, 6 E$ ). In the thalamus and hypothalamus of the $\mathrm{P} 7$ brain, binding sites were spread throughout all subdivisions (Fig. 6C), differing from that in the adult brain, in which only selective subdivisions of these structures expressed dense binding sites.

In the immature cerebellum, there was no distinct pattern of high (cortex) and low (white matter) binding zones as seen in the mature cerebellum (Fig. 9G,H). Although binding sites in the brainstem were only detected in a few areas at the adult stage, a widespread distribution of dense binding sites in these structures was noted in the immature brain (Fig. 9D,H). For example, all layers of the superior colliculus displayed binding sites at almost the same level of density (Fig. 9D). Again, both the pars reticulata and pars compacta of the substantia nigra expressed a large number of binding sites (Fig. 9D,E). In cross sections of the pons and medulla oblongata, binding sites were widely diffused in the early postnatal brains. In fact, most midbrain and brainstem nuclei, including red (Fig. 9E), facial (Fig. 9G), and trigeminal (Fig. 9H) nuclei, showed dense binding sites in the immature brain. 


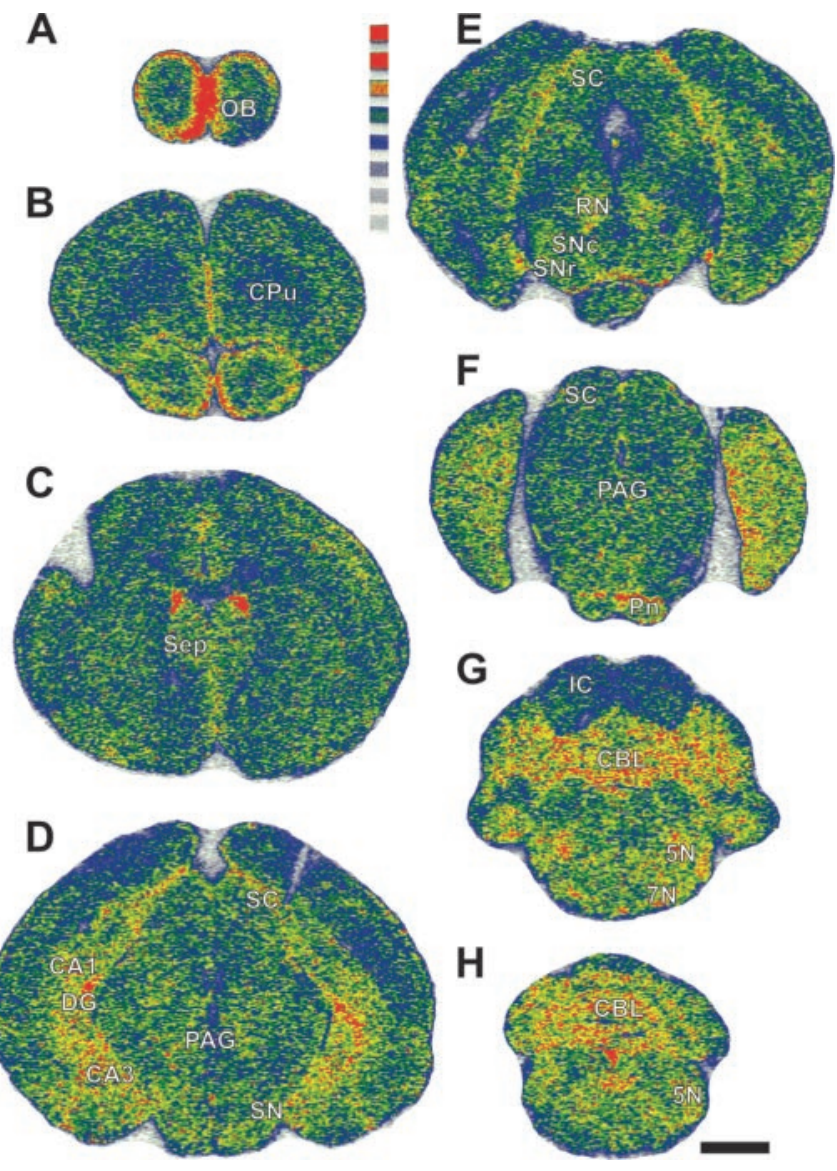

Figure 9. Distribution pattern of $\left[{ }^{3} \mathrm{H}\right]$ compound $\mathrm{D}$ binding sites in a $\mathrm{P} 7 \mathrm{rat}$ brain. Note that the binding sites are diffusely distributed across the entire brain, and several brainstem nuclei, including the red $(\mathrm{RN} ; E)$, facial $(7 \mathrm{~N} ; G)$, and trigeminal $(5 \mathrm{~N} ; H)$ nuclei, exhibit dense binding sites at this stage. For other abbreviations, see Figure 3. Scale bar, $1 \mathrm{~mm}$.

\section{Effect of deafferentation on binding density}

The presence of a high density of binding sites in the olfactory glomeruli suggests an association of these binding sites with the glomerular synaptic terminals. To further assess the relationship of the binding sites with neuronal terminals, we studied the effect of deafferentation on binding site change in the olfactory bulb. For quantitative comparison of binding density between rats, every tenth bulbar section from the level of the first appearance of the subependymal layer to the level just passed the accessory olfactory bulb was studied. First, autoradiograms and Nissl stain images (caught with a digital camera) of the same selected section were placed side by side. A measuring template was created by tracing the glomerular layer over the Nissl stain image. Next, the template was moved over to cover and measure the binding density in the glomerular layer in the autoradiograms. An apparent reduction with subsequent recovery of binding density was observed in the glomerular layer and the olfactory epithelium after $\mathrm{ZnSO}_{4}$ nasal infusion (Fig. $10 A-C$ ). The binding density in the glomerular layer was reduced by $>60 \%$ at $24 \mathrm{hr}$ and $50 \%$ at $7 \mathrm{~d}$ after the lesion (Fig. 10A,C). Thereafter, the binding sites began to recover, and at 2, 4, and 6 weeks after the lesion, $\sim 50,70$, and $80 \%$, respectively, of the binding density reappeared in the glomerular layer. We also examined the binding sites in the intact and lesioned nasal epithelium. The density in the olfactory epithelium was measured in the sections passing through the caudal portion of the nasal cavity with at least three turbinates presented. The sampled region covered the epithelium lining the upper third of the nasal septum and the roof of the nasal vault (Fig. $10 \mathrm{~B}$ ). In the intact nasal epithelium, binding sites were more concentrated in the so-called nerve epithelium where the olfactory sensory neurons reside. These regions include the epithelium lining the upper portion of the nasal septum, the roof of the nasal cavity, and the upper turbinate (Fig. $10 \mathrm{~B}$ ). The initial reduction of binding density in the olfactory epithelium was 50\% at $24 \mathrm{hr}$ after the lesion (Fig. $10 \mathrm{~B}, \mathrm{C}$ ), but recovery of binding density in the epithelium appeared quicker compared with that in the glomeruli. Thus, the density of binding sites in the epithelium reached $>70$ and $90 \%$ of control values by 2 and 3 weeks after the lesion. It should be noted that the thickness of the epithelium did not return to the control levels even 6 weeks after the lesion (Fig. $10 B)$.

\section{Discussion}

Using $\gamma$-secretase inhibitors as markers, this study attempts to localize $\gamma$-secretase, especially the putative active sites, in the brain. Characterizations using PS-1 knock-out mice yield a correlation between the density of $\gamma$-secretase inhibitor binding and the level of PS-1 gene expression. Pharmacological profiling using different unlabeled $\gamma$-secretase inhibitors is consistent with the notion that the radiolabeled inhibitors are likely to bind at the $\mathrm{N}$ - and C-terminal fragments of PS. In the adult rat brain, the binding sites are predominantly present in the forebrain (mostly in the olfactory bulb, cerebral cortex, and hippocampal formation) and cerebellum. Several brainstem areas, e.g., substantia nigra pars reticulata $(\mathrm{SNr})$ and the superior colliculus, display strong binding, whereas most relay nuclei across the thalamus and brainstem show little binding. In some brain areas, e.g., the olfactory glomeruli and cerebellar cortex, the binding sites concentrate in regions dominated by neuronal terminals. In the developing brain, the binding sites are transiently overexpressed and diffusely distributed at the early postnatal stage. The results from deafferentation experiments suggest a close association of the binding sites with degeneration and regeneration of the olfactory nerve terminals.

In general, our data support the idea that PS constitutes a key component of $\gamma$-secretase complex (Selkoe, 2001; De Strooper, 2003, Kimberly et al., 2003). First, knock-out of the PS-1 gene in the homozygous (PS-1 ${ }^{-l-}$ ) mice causes $80 \%$ reduction of the $\gamma$-secretase inhibitor binding, indicating a dependence of the binding sites to the presence of the PS-1 protein. The remaining $20 \%$ of binding may be contributed by PS-2 expression. Second, the overall topographic pattern of $\gamma$-secretase inhibitor binding sites in the adult rat brain overlaps extensively with that of PS-1 and PS-2 mRNA expression (Lee et al., 1996; Page et al., 1996; Takami et al., 1997). Finally, the postnatal developmental pattern of binding sites is virtually comparable with that of PS- 1 mRNA expression with characteristics of overexpression but homogeneous localization in the first 2-3 postnatal weeks (MorenoFlores et al., 1999).

The use of potent and selective small $\gamma$-secretase inhibitors may be considered a uniqueness of this study for mapping $\gamma$-secretase in the brain. The compounds used in the present study reduce $\mathrm{A} \beta$ production with nanomolar potencies, and there appears a parallelism of the pharmacological efficacy and the competition binding $\mathrm{IC}_{50}$ values from cell-based systems (Seiffert et al., 2000; Beher et al., 2001) as well as brain sections in the present study. Therefore, the location of binding sites may represent both anatomical and functional elements with regard to the enzyme in a given brain region. Although the exact structures of the enzymatic center of $\gamma$-secretase are yet to be determined, the 
competition binding data appear to be consistent with the notion that our ligands may bind at the $\mathrm{N}$ - and C-terminal fragments of PS, the putative active sites of PS for $\gamma$-site cleavage. Thus, $\left[{ }^{3} \mathrm{H}\right]$ compound $\mathrm{D}$ binding in brain sections is completely displaceable by compound $\mathrm{C}$ and L-685,458, which have been previously shown to target at the $\mathrm{N}$ - and C-terminal fragments (Seiffert et al., 2000, Li et al., 2000). This may explain the phenomenon that the distribution of the inhibitor binding sites in the brain in this study is generally much more differential and selective compared with the distribution of PS immunolabeling in earlier studies (Elder et al., 1996; Lee et al., 1996; Moussaoui et al., 1996; Page et al., 1996; Blanchard et al., 1997; Kim et al., 1997; Takami et al., 1997).

A novel finding of this study is the differential sub-regional or laminar distribution of $\gamma$-secretase inhibitor binding sites compared with PS mRNA expression in many brain areas. In the cerebellar cortex, the binding sites concentrate in the molecular layer, whereas PS-1 and PS-2 transcripts reside mostly in the Purkinje cell and granule cell layers (Lee et al., 1996). The enriched binding in the molecular layer may reflect a preferential localization of the functional PS sites in neuronal processes and synaptic terminals, the major neuronal components of the molecular layer. This is consistent with the electron microscopic localization of PS-1 immunolabeling in the mossy and parallel fiber terminals and the dendritic spines of Purkinje cells (Ribaut-Barassin et al., 2000). In the hippocampal formation, binding density is higher in CA3 and hilus than CA1, CA2, and the granule cell layer, whereas PS $\mathrm{mR}$ NAs are evenly expressed across the pyramidal and granule cell layers (Lee et al., 1996; Page et al., 1996). The enhanced binding in CA3 and hilus may indicate an association of the binding sites with mossy fiber synaptic terminals, in agreement with the findings of PS-1 immunolabeling in the stratum lucidum of CA3 (Lee et al., 1996) and in the presynaptic and postsynaptic terminals of the mossy fibers at the electron microscopic level (Ribaut-Barassin et al., 2000). In the $\mathrm{SN}, \gamma$-secretase inhibitor binding sites are present only in the $\mathrm{SNr}$ but not the substantia nigra pars compacta (SNc), whereas the PS transcripts are minimal in both the SNr and SNc (Lee et al., 1996). This preferential labeling of the $\mathrm{SNr}$ suggests a possible association of the binding sites with the axon terminals from extranigral origins, e.g., striatum and subthalamic nuclei (Fallon and Loughlin, 1995).

The extremely dense binding sites in the olfactory glomeruli also suggest preferential localization of the binding in synaptic terminals, the major neuronal components in these regions. The results from our deafferentation experiments support and extend this notion. Thus, after a chemical lesion of nasal epithelium, the binding sites in the glomeruli are reduced significantly in the first several days and then recover and eventually reach the prelesion levels. These changes correspond to the deafferentation-induced degeneration of olfactory sensory neurons and their axons and a subsequent regeneration of the pathway, respectively. The more rapid recovery of binding density in the epithelium relative to the glomeruli is consistent with the lag between the formation of the sensory neuronal somata and the arrival of their growing axons at the glomerular targets (Herzog and Otto, 1999).

Brain regions expressing strong binding for $\gamma$-secretase inhibitors appear, in general, to be those retaining a high neuroplasticity and that are responsible for higher brain functions. For example, the olfactory bulb and hippocampal formation are considered the brain areas with the highest neuroplasticity in light of dynamic and continuous neuronal and synaptic renewal, with the latter occurring mostly in the glomeruli and mossy fiber terminal fields (Altman, 1969; Bayer et al., 1982; Calof et al., 1996; Ramirez-Amaya et al., 2001; Rochefort et al., 2002). These two brain areas, together with other cortical structures, the hypothalamus and the anteriomedial thalamus, are critical for brain functions such as self-awareness, perception, learning, and memory, which require constant and lifelong neuronal and synaptic re- 
modeling to meet environmental demands (Gould et al., 1999; Arendt, 2001). The cerebellum and the striatonigral system are involved in coordinated motor activities as well as certain higher brain functions such as working memory, decision making, and language (Graybiel, 1995; Marien et al., 2001; Herrero et al., 2002). Unlike the above areas with high binding, most of the relay nuclei in the posteriolateral thalamus and brainstem show little binding. One may assume that these lower brain centers have relatively rigid synaptic connections conserved for stabilized principal neuronal functions, i.e., basic motor and sensory signal relay (Arendt, 2001).

Apparently, many brain regions enriched with the binding sites also express high levels of APP and are vulnerable to A $\beta$ deposition. For example, in the rodent, the entire olfactory pathway expresses high levels of PS and APP (Card et al., 1988; Lee et al., 1996; Page et al., 1996; Utsumi et al., 1998), whereas in the human, this system appears affected first and most severely in AD (Braak and Braak, 1998; Kovacs et al., 2001). The same situation exists for the hippocampal formation. Thus, our study supports the view that an abundance of $\gamma$-secretase and APP in selected brain regions renders a higher vulnerability of these regions to $\mathrm{A} \beta$ deposition and neurodegeneration that may lead to neuropsychological dysfunction. Therefore, pharmacological intervention of abnormal processing of APP by using $\gamma$-secretase inhibitors may have a potential utility for $\mathrm{AD}$ therapy.

Neurogenesis in the rat brain is mostly completed by birth, with neuronal differentiation and migration continuing for several weeks (Miale and Sidman, 1961; Bayer, 1980). Synaptogenesis is also active during the first 3 weeks (Bahr and Wolff, 1985; Miller, 1986; Morara et al., 2001; Marty et al., 2002). The pronounced expression of $\gamma$-secretase in the early postnatal brain therefore coincides with the major events of neuronal differentiation and maturation, synaptogenesis and remodeling, and lamination and pattern formation (Wittenburg et al., 2000; Yu et al., 2001; Figueroa et al., 2002; Sarkar and Das, 2003).

Taken together, this is the first report of using selective enzymatic inhibitors as probes to access the in situ distribution of $\gamma$-secretase, especially the putative active sites, in the developing and adult brain and in a model of neuronal degeneration, regeneration, and plasticity. Our results support the notion that $\gamma$-secretase plays a physiological role in neuronal development, maturation, and plasticity. Also, the distribution pattern of $\gamma$-secretase inhibitor binding sites in the adult brain is consistent with a possible involvement of the enzyme in $\mathrm{AD}$ pathogenesis.

\section{References}

Altman J (1969) Autoradiographic and histological studies of postnatal neurogenesis: IV. Cell proliferation and migration in the anterior forebrain, with specific reference to persisting neurogenesis in the olfactory bulb. J Comp Neurol 137:433-458.

Arendt T (2001) Alzheimer's disease as a disorder of mechanisms underlying structural brain self-organization. Neuroscience 102:723-765.

Bahr B, Wolff JR (1985) Postnatal development of axosomatic synapses in rat visual cortex: morphogenesis and quantitative evaluation. J Comp Neurol 233:405-420.

Bayer SA (1980) Development of the hippocampal region in the rat II: morphogenesis during embryonic and early postnatal life. J Comp Neurol 190:115-134.

Bayer SA, Yackel JW, Puri PS (1982) Neurons in the rat dentate gyrus granular layer substantially increase during juvenile and adult life. Science 216:890-892.

Beher D, Wrigley JD, Nadin A, Evin G, Masters CL, Harrison T, Castro JL, Shearman MS (2001) Pharmacological knock-down of the presenilin 1 heterodimer by a novel gamma secretase inhibitor: implications for presenilin biology. J Biol Chem 276:45394-45402.

Blanchard V, Czech C, Bonici B, Clavel N, Gohin M, Dalet K, Revah F, Pradier
L, Imperato A, Moussaoui S (1997) Immunohistochemical analysis of presenilin 2 expression in the mouse brain: distribution pattern and colocalization with presenilin 1 protein. Brain Res 758:209-217.

Braak H, Braak E (1998) Evolution of neuronal changes in the course of Alzheimer's disease. J Neural Transm [Suppl] 53:127-140.

Calof AL, Hagiwara N, Holcomb JD, Mumm JS, Shou J (1996) Neurogenesis and cell death in olfactory epithelium. J Neurobiol 30:67-81.

Card JP, Meade RP, Davis LG (1988) Immunocytochemical localization of the precursor protein for beta-amyloid in the rat central nervous system. Neuron 1:835-846.

De Strooper B (2003) Aph-1, pen-2, and nicastrin with presenilin generate an active gamma-secretase complex. Neuron 10:38:9-12.

De Strooper B, Saftig P, Craessaerts K, Vanderstichele H, Guhde G, Annaert W, Von Figura K, Van Leuven F (1998) Deficiency of presenilin-1 inhibits the normal cleavage of amyloid precursor protein. Nature 391:387-390.

Elder GA, Tezapsidis N, Carter J, Shioi J, Bouras C, Li HC, Johnston JM, Efthimiopoulos S, Friedrich Jr VL, Robakis NK (1996) Identification and neuron specific expression of the S182/presenilin-1 protein in human and rodent brain. J Neurosci Res 45:308-320.

Esler WP, Kimberly WT, Ostaszewski BL, Diehl TS, Moore CL, Tsai JY, Rahmati T, Xia W, Selkoe DJ, Wolfe MS (2000) Transition-state analogue inhibitors of gamma-secretase bind directly to presenilin-1. Nat Cell Biol 2:428-434.

Fallon JH, Loughlin SE (1995) Substantia nigra. In: The rat nervous system, Ed 2 (Paxinos G, ed), pp 215-237. San Diego: Academic.

Figueroa DJ, Morris JA, Ma L, Kandpal G, Chen E, Li YM, Austin CP (2002) Presenilin-dependent gamma-secretase activity modulates neurite outgrowth. Neurobiol Dis 9:49-60.

Gould E, Tanapat P, Hastings NB, Shors TJ (1999) Neurogenesis in adulthood: a possible role in learning. Trends Cogn Sci 3:186-192.

Graybiel AM (1995) Building action repertoires: memory and learning functions of the basal ganglia. Curr Opin Neurobiol 5:733-741.

Herreman A, Serneels L, Annaert W, Collen D, Schoonjans L, De Strooper B (2000) Total inactivation of gamma-secretase activity in presenilindeficient embryonic stem cells. Nat Cell Biol 2:461-462.

Herrero MT, Barcia C, Navarro M (2002) Functional anatomy of thalamus and basal ganglia. Childs Nerv Syst 18:386-404.

Herzog C, Otto T (1999) Regeneration of olfactory receptor neurons following chemical lesion: time course and enhancement with growth factor administration. Brain Res 849:155-161.

Kamal A, Almenar-Queralt A, LeBanc JF, Roberts EA, Glodstein LSB (2001) Kenesin-mediated axonal transport of a membrane compartment containing $\beta$-secretase and presenilin-1 requires APP. Nature 414:643-648.

Kim KS, Wegiel J, Sapienza V, Chen J, Hong H, Wisniewski HMJ (1997) Immunoreactivity of presenilin-1 in human, rat and mouse brain. Brain Res 757:159-163.

Kimberly WT, Xia W, Rahmati T, Wolfe MS, Selkoe DJ (2000) The transmembrane aspartates in presenilin 1 and 2 are obligatory for gammasecretase activity and amyloid beta-protein generation. J Biol Chem 275:3173-3178.

Kimberly WT, LaVoie MJ, Ostaszewski BL, Ye W, Wolfe MS, Selkoe DJ (2003) $\gamma$-Secretase is a membrane protein complex comprised of presenilin, nicastrin, aph-1, and pen-2. Proc Natl Acad Sci USA 100:6382-6387.

Kornilova AY, Das C, Wolfe MS (2003) Differential effects of inhibitors on the gamma-secretase complex: mechanistic implications. J Biol Chem 278:16470-16473.

Kovacs T, Cairns NJ, Lantos PL (2001) Olfactory centres in Alzheimer's disease: olfactory bulb is involved in early Braak's stages. NeuroReport 12:285-288.

Lee MK, Slunt HH, Martin LJ, Thinakaran G, Kim G, Gandy SE, Seeger M, Koo E, Price DL, Sisodia SS (1996) Expression of presenilin 1 and 2 (PS1 and PS2) in human and murine tissues. J Neurosci 16:7513-7525.

Li T, Ma G, Cai H, Price DL, Wong PC (2003) Nicastrin is required for assembly of presenilin/gamma-secretase complexes to mediate notch signaling and for processing and trafficking of $\beta$-amyloid precursor protein in mammals. J Neurosci 23:3272-3277.

Li YM, Xu M, Lai MT, Huang Q, Castro JL, DiMuzio-Mower J, Harrison T, Lellis C, Nadin A, Neduvelil JG, Register RB, Sardana MK, Shearman MS, Smith AL, Shi XP, Yin KC, Shafer JA, Gardell SJ (2000) Photoactivated 
gamma-secretase inhibitors directed to the active site covalently label presenilin 1. Nature 405:689-694.

Marien P, Engelborghs S, De Deyn PP (2001) Cerebellar neurocognition: a new avenue. Acta Neurol Belg 101:96-109.

Marty S, Wehrle R, Alvarez-Leefmans FJ, Gasnier B, Sotelo C (2002) Postnatal maturation of $\mathrm{Na}+, \mathrm{K}+, 2 \mathrm{Cl}-$ cotransporter expression and inhibitory synaptogenesis in the rat hippocampus: an immunocytochemical analysis. Eur J Neurosci 15:233-245.

Miale IL, Sidman (1961) An autoradiographic analysis of histogenesis in mouse cerebellum. Exp Neurol 4:277-296.

Miller MW (1986) Maturation of rat visual cortex. III. Postnatal morphogenesis and synaptogenesis of local circuit neurons. Brain Res 390:271-285.

Morara S, van der Want JJ, de Weerd H, Provini L, Rosina A (2001) Ultrastructural analysis of climbing fiber-Purkinje cell synaptogenesis in the rat cerebellum. Neuroscience 108:655-671.

Moreno-Flores MT, Medina M, Wandosell F (1999) Expression of presenilin 1 in nervous system during rat development. J Comp Neurol 410:556-570.

Moussaoui S, Czech C, Pradier L, Blanchard V, Bonici B, Gohin M, Imperato A, Revah F (1996) Immunohistochemical analysis of presenilin-1 expression in the mouse brain. FEBS Lett 383:219-222.

Page K, Hollister R, Tanzi RE, Hyman BT (1996) In situ hybridization analysis of presenilin 1 mRNA in Alzheimer disease and in lesioned rat brain. Proc Natl Acad Sci USA 93:14020-14024.

Podlisny MB, Citron M, Amarante P, Sherrington R, Xia W, Zhang J, Diehl T, Levesque G, Fraser P, Haass C, Koo EH, Seubert P, St. George-Hyslop P, Teplow DB, Selkoe DJ (1997) Presenilin proteins undergo heterogeneous endoproteolysis between Thr291 and Ala299 and occur as stable Nand C-terminal fragments in normal and Alzheimer brain tissue. Neurobiol Dis 3:325-337.

Ramirez-Amaya V, Balderas I, Sandoval J, Escobar ML, Bermudez-Rattoni F (2001) Spatial long-term memory is related to mossy fiber synaptogenesis. J Neurosci 21:7340-7348.

Ribaut-Barassin C, Moussaoui S, Brugg B, Haeberle AM, Huber G, Imperato A, Delhaye-Bouchaud N, Mariani J, Bailly YJ (2000) Hemisynaptic distribution patterns of presenilins and beta-APP isoforms in the rodent cerebellum and hippocampus. Synapse 35:96-110.

Rochefort C, Gheusi G, Vincent JD, Lledo PM (2002) Enriched odor exposure increases the number of newborn neurons in the adult olfactory bulb and improves odor memory. J Neurosci 22:2679-2689.

Sarkar SN, Das HK (2003) Regulatory roles of presenilin-1 and nicastrin in neuronal differentiation during in vitro neurogenesis. J Neurochem 87:333-343.

Seiffert D, Bradley JD, Rominger CM, Rominger DH, Yang F, Meredith Jr JE, Wang Q, Roach AH, Thompson LA, Spitz SM, Higaki JN, Prakash SR, Combs AP, Copeland RA, Arneric SP, Hartig PR, Robertson DW, Cordell B, Stern AM, Olson RE, Zaczek R (2000) Presenilin-1 and -2 are molec- ular targets for gamma-secretase inhibitors. J Biol Chem 275:34086-34091.

Selkoe DJ (2001) Alzheimer's disease: genes, proteins, and therapy. Physiol Rev 81:741-766.

Takami K, Terai K, Matsuo A, Walker DG, McGeer PL (1997) Expression of presenilin- 1 and -2 mRNAs in rat and Alzheimer's disease brains. Brain Res 748:122-130.

Thinakaran G, Borchelt DR, Lee MK, Slunt HH, Spitzer L, Kim G, Ratovitsky T, Davenport F, Nordstedt C, Seeger M, Hardy J, Levey AI, Gandy SE, Jenkins NA, Copeland NG, Price DL, Sisodia SS (1996) Endoproteolysis of presenilin 1 and accumulation of processed derivatives in vivo. Neuron 17:181-190.

Tian G, Ghanekar SV, Aharony D, Shenvi AB, Jacobs RT, Liu X, Greenberg BD (2003) The mechanism of gamma-secretase: multiple inhibitor binding sites for transition state analogs and small molecule inhibitors. J Biol Chem 278:28968-28975.

Utsumi M, Sato K, Tanimukai H, Kudo T, Nishimura M, Takeda M, Tohyama M (1998) Presenilin-1 mRNA and beta-amyloid precursor protein mRNA are expressed in the developing rat olfactory and vestibulocochlear systems. Acta Otolaryngol 118:549-553.

Vassar R, Bennett BD, Babu-Khan S, Kahn S, Mendiaz EA, Denis P, Teplow DB, Ross S, Amarante P, Loeloff R, Luo Y, Fisher S, Fuller J, Edenson S, Lile J, Jarosinski MA, Biere AL, Curran E, Burgess T, Louis JC, Collins F, Treanor J, Rogers G, Citron M (1999) Beta-secretase cleavage of Alzheimer's amyloid precursor protein by the transmembrane aspartic protease BACE. Science 286:735-741.

Verbeek MM, Ruiter DJ, de Waal RM (1997) The role of amyloid in the pathogenesis of Alzheimer's disease. Biol Chem 378:937-950.

Wittenburg N, Eimer S, Lakowski B, Rohrig S, Rudolph C, Baumeister R (2000) Presenilin is required for proper morphology and function of neurons in C. elegans. Nature 406:306-309.

Wolfe MS, Xia W, Ostaszewski BL, Diehl TS, Kimberly WT, Selkoe DJ (1999) Two transmembrane aspartates in presenilin-1 required for presenilin endoproteolysis and gamma-secretase activity. Nature 398:513-517.

Wong PC, Zheng H, Chen H, Becher MW, Sirinathsinghii DJ, Trumbauer ME, Chen HY, Price DL, Van der Ploeg LH, Sisodia SS (1997) Presenilin 1 is required for Notchl and DIIl expression in the paraxial mesoderm. Nature 387:288-292.

Yan R, Bienkowski MJ, Shuck ME, Miao H, Tory MC, Pauley AM, Brashier JR, Stratman NC, Mathews WR, Buhl AE, Carter DB, Tomasselli AG, Parodi LA, Heinrikson RL, Gurney ME (1999) Membrane-anchored aspartyl protease with Alzheimer's disease beta-secretase activity. Nature 402:533-537.

Yu H, Saura CA, Choi SY, Sun LD, Yang X, Handler M, Kawarabayashi T, Younkin L, Fedeles B, Wilson MA, Younkin S, Kandel ER, Kirkwood A, Shen J (2001) APP processing and synaptic plasticity in presenilin-1 conditional knockout mice. Neuron 31:713-726. 